\section{The integrated reporting system: a new accountability enhancement tool for public sector entities}

\section{Tudor OPRISSOR,} Babeş-Bolyai University of Cluj-Napoca, E-mail: tudor.oprisor@econ.ubbcluj.ro

Adriana TIRON-TUDOR, Babeş-Bolyai University of Cluj-Napoca, E-mail: adriana.tiron@ubbcluj.ro

Cristina Silvia NISTOR, Babeş-Bolyai University of Cluj-Napoca, E-mail: cristina.nistor@econ.ubbcluj.ro

\section{Alstract}

In the recent years, integrated reporting has made progress towards becoming an efficient communication instrument that would bring an active contribution to the financial stability and sustainability of the economic environment. This paper employs mainly a documentary research approach and aims to track one of the main prerequisites leading towards new trends in public sector reporting - the concept of "public accountability", and pinpoint the existing evidence which supports the perspective of adopting an integrated reporting system for public entities. Also, the authors emphasize the reaction from practitioners to the idea of "integrated reporting for the public sector" and analyse the frontrunning application of hybrid forms of reporting (e.g. City of Warsaw Integrated Sustainability Report), as well as the profile of the "Integrated Reporting - Public Sector Pioneer Network.". Findings show that integrated reporting is gaining momentum towards application in the case of public sector entities, but advancements are rather slow. Due to the scarcity of data from reporting practice regarding integrated reports in the public sector (as the Pioneer Network is currently under development), which makes it difficult to construct an empirical study with actual evidence, the authors use extrapolation and knowledge transference from existing proof of hybrid forms of reporting.

Keywords: Integrated reporting, public sector, accountability, integrated thinking.

JEL Classification: M41.

To cite this article:

Oprişor, T., Tiron-Tudor, A. and Nistor, C.S. (2016), The integrated reporting system: a new accountability enhancement tool for public sector entities, Audit Financiar, vol. XIV, no. 7(139)/2016, pp. 749-762, DOI: 10.20869/AUDITF/2016/139/749

To link to this article:

http://dx.doi.org/10.20869/AUDITF/2016/139/749 


\section{Introduction}

Disclosure enhancement requirements are always causing "mutations" in the reporting systems, as organizations from all sectors are attempting to fulfil the information needs of their stakeholders and mitigate potential conflicts of interest between different categories of information users. One natural outcome of these so-called "mutations" is the integrated reporting system $(<\mid R>)$, which is a way of an efficient communication on the holistic view of an organization's activity (including both financial and non-financial dimensions).

The concept gained traction as the main governing body - the International Integrated Reporting Council (IIRC) undertook a lot of effort to promote it and provide guidance and delineations so that its implementation would be eased. Thus, the Consultation Draft for the Conceptual Framework was issued in April 2013 (IIRC, 2013a), with a refined proposal for all the principles, fundamental concepts and content elements for an integrated report. In December 2013, the IIRC issued the final version of the Conceptual Framework (IIRC, 2013b), which embedded the feedback received through the comment letters from various stakeholders (reporting entities, professional organizations, standard setters, auditors, academics etc.).

Also, simultaneous initiatives have been launched to provide further guidance on $\langle\mid R\rangle$. In this respect, professional organizations have been involved in this process. Their contribution to the development of the framework is seen in the form of the $<\mid R>$ Background Papers and they approach specific topics, such as the business model (CIMA, IFAC and PwC, 2013); the capitals (ACCA and NBA, 2013); the connectivity of information principle ( $\mathrm{WICl}, 2013)$; materiality (AICPA, 2013).

According to the $<\mathrm{R}>$ Conceptual Framework (paragraph 1.1), "an integrated report is a concise communication about how an organization's strategy, governance, performance and prospects, in the context of its external environment, lead to the creation of value over the short, medium and long term" (IIRC, 2013b). This generally-accepted definition represents the main ground for the integration process within an organization (regarding financial and non-financial elements), as well as the planned outputs resulting from predefined procedures. Furthermore, the definition outlines the elements of "architecture" of an integrated reporting system, therefore intending to facilitate a better understanding of the processes which take place within an entity, as well as the results of the reporting entity's activity.

While this system was designed to be implemented by companies, new developments have emerged leading it towards other sectors (such as the public and not-forprofit sectors), but without clear and distinct delineations to this extent. Moreover, to some degree, the idea of implementing $<\mid R>$ in the public and not-for-profit sector was met with reluctance by a part of the practitioners, mostly by advocates of the $\langle\mid \mathrm{R}\rangle$ design for the private sector. However, the professional organizations and standard setters - through the comment letters submitted in the consultation process - emphasized development directions towards the public sector and rallied behind the idea that $\langle\mathbb{R}\rangle$ would have good implementation perspectives for these entities (thus creating and promoting initiatives, such as the $\langle\mathbb{R}\rangle$ Public Sector Pioneer Network).

The primary objective of this paper is to identify the prerequisites for public "integrated thinking" and to argue for applying integrated reporting for the public sector as a useful accountability-enhancing tool, as well as a disclosure instrument for the impact of the entities' activity.

Accordingly, our research questions to which we attempt to provide answers are the following:

\section{Is integrated reporting a suitable reporting system for} public sector entities?

\section{Can integrated reporting enhance accountability for public sector entities?}

In the way this paper is constructed, the main contribution would be towards a better understanding of the prerequisites of \langle|$R>$ in the context of public sector implementation. Furthermore, this would concur to enabling $\langle\mathrm{R}\rangle$ as an efficient communication tool between the reporting entities (as stewards of public resources) and the users of accounting information (among which are accounting professionals, including auditors). Auditing $\langle\mathbb{R}\rangle$ is, in itself, a controversial and well-debated topic. Any increase in the level of understanding regarding the delineations and the (possibly) adjusted $\langle\mid \mathrm{R}\rangle$ model for public sector entities is highly relevant in terms of research value. 


\section{Research methodology}

To accomplish our research objective, we turn towards the literature and analyse what the frontrunners from this research field have done. We develop a brief review of the relevant literature and evidence from practice to gain a better level of knowledge on how integrated reporting has evolved and what future directions there are for its development. In this respect, we reveal that our research is on a documentary level and our research methods are the review, the argumentative structure and content analysis.

Most of the papers and reports that we found and used in our literature review regarding integrated reporting are targeted towards the implementation of $\langle\mid \mathrm{R}\rangle$ in the private sector, as this is the benchmark and the primary example of good practice. Therefore, we undertook a breakdown of the integrated reporting construct and attempted to identify the prerequisites for its implementation in the public sector (so that we could create an argument for the development of $\langle\mid R\rangle$ as an accountability tool in public sector entities).

Consequently, we select public accountability as a link between the sectors and a way of transferring the knowhow in the case of public sector adoption of $\langle\mid \mathrm{R}\rangle$. We attempt to identify key delineations (in terms of definition, taxonomy, evolution over time and embedment in reporting systems), links to precursor models based on integrated thinking (such as sustainability reporting, which relies on the triple bottom line) and, ultimately, inference in the $<\mid R>$ model (based on the mentioned taxonomy).

Also, we study the architecture of the $<\mid R>$ Framework and question how the key dimensions could be addressed for the public sector entities. In our assumption, in the case of public sector entities, instances of public accountability exist on every layer of the $<\mid R>$ model (both on a static view - when addressing resource allocation and on a dynamic view when discussing value creation). After all, the IIRC clearly states within the Framework that one of their aims is "to enhance accountability and stewardship for the broad base of capitals [...] and promote understanding of their interdependencies" (IIRC, 2013b: p. 2).

Last, but not least, we emphasize the existing cases and projects in development for $\langle\mathbb{R}\rangle$ in the public sector. Although their number is not that high, these cases are the practical manifestations of the (tentative) implementation process started by the IIRC and its collaborators. Research and discussions in this direction are gaining traction, and we expect to see an intensification of the initiatives leading towards $\langle\mid R\rangle$ in the public sector.

Being publicly accountable is an inherent trait of public servants (and, by extension, of public sector organizations). Therefore, we frame our motivation for considering $\langle\mid R\rangle$ as an accountability tool in the context of practical communication needs. As the public sector has a broader range of stakeholders (and a part of them do not have a high degree of economic literacy), many of them do not necessarily need more disclosure, but an efficient one (and by "efficient" we mean a form of reporting where the users can understand from a concise communication as many aspects as possible regarding the use of resources and the impact of the organization's activity).

Clearly, $<\mid R>$ could have many implications in the case of public sector entities other than safeguarding accountability and it can be linked to different principles and theories which were also a basis for precursor forms of reporting. Having said that, we consider public accountability as an intrinsic attribute of public sector entities which leads to the need for reporting system restructuring towards $\langle\mid R\rangle$ (said otherwise, into a model that would comprise as many elements of public resource use in an intelligible and comprehensive manner).

\section{Theoretical insights on the concent of public accountability: a prerequisite for integrated reporting}

Even if it generates many debates in the literature, accountability - as a concept - still presents significant problems of interpretation. Generally speaking, accountability indicates "the aptitude of subjects (accountee or steward) to account for their actions, and for their actions in relation to another person or group of people (accountor or principal)". Therefore, the key conceptual delineation revolves around the agency theory, respectively: there is a relationship between a subject, who acts in the interest of another, and towards whom he has some form of obligation to make himself 
accountable (Stewart, 1984, cited by Bartocci and Picciaia, 2013: p. 192).

To provide a better understanding of the delineations regarding accountability, Patton (1992) conducted a comprehensive study concerning the concept of accountability. He mainly focused on the link between the idea of accountability and the governmental financial reporting, presenting the approach of the GASB from the United States of America (which states that "[g]overnment financial reporting should provide information to assist users in (a) assessing accountability and (b) making economic, social and political decisions [...]"). Nevertheless, many other inherent issues and limitations are prone to appear, such as the inconsistent meaning of "accountability" - as a term; the complications brought to the cost-benefit analysis of information; the hindrance in assuring the provision of sufficient information in a single report for all users; the existence of "non-accounting-based means of achieving accountability".

In Patton's (1992) view, "accountability reporting in complex environments with many dimensions of accountability (for instance, legal, political, financial, etc.) would imply eclectic reports that include both financial data and a variety of other forms of information". These dimensions can be addressed separately, as Burrit (2012) does with environmental performance accountability, or even more interesting, all together. This would constitute the essential ground of having a report which encompasses disclosures for most (if not all) of the capitals of an organization.

In itself, accountability has become a trending principle. It has even been included in the "Seven Principles of Public Life" (alongside selflessness, integrity, objectivity, openness, honesty and leadership), issued by the Nolan Committee from the UK. Also, the South African Public Service Commission considers the systematic building and incremental development of both capacity and capability as core enablers of public service. In other words, an accreditation system for public service managers is highly recommended to ensure that appointees have the required set of skills and experience for their work (Raga and Taylor, 2005).

Mashaw (2006, p. 118) develops a framework proposal starting with a taxonomy formed from six lines of inquiry which - in his opinion - constitute the layers of an accountability regime: "who, to whom, about what, through what processes, by what standards and with what effect". This taxonomy allows the careful dimensional analysis of any reporting system, especially one with a holistic approach, such as $\langle\mid \mathrm{R}\rangle$, and identify all the key actors and informational flows in-depth.

We notice that, over time, stakeholders have become increasingly demanding concerning the quality of the governing process, transparency and accountability of public sector organizations. Hence, $\langle\mathbb{R}\rangle$ is a tool able to provide an accurate level of insight into how the reporting entity is governed and which are the sources of information in the decision-making process, respectively how management structures are held accountable for performance (KPMG, 2012).

The principle of stakeholder engagement (which is also an essential element in the $\langle\mid R\rangle$ construct) is also viewed as a fundamental accountability mechanism, mandating organizations to involve their stakeholders in identifying, comprehending and responding to sustainability concerns as well as to issue reports, and provide explanations and answers to stakeholders regarding their decisions, actions and performance (AccountAbility, 2011: p. 6, cited by Steyn and de Beer, 2012: p. 61).

The concept of $\langle\mid R\rangle-$ i.e. disclosing financial and nonfinancial information about governance, performance and risk management in a holistic manner within the same document - is perceived as a necessary, forwardlooking upgrade of sustainability reporting. These $\langle\mid R\rangle$ guidelines have been argued to support the information needs of long-term investors (favoured to, but not excluding other groups of interested parties), by showing the broader and longer-term social and environmental consequences of decision-making. $<\mid R>$ puts strategic financial and non-financial information at the same level of importance for performance disclosure and stakeholder accountability (Synergiz, 2014).

Returning our focus on precursor reporting models of publicly accountable entities, we identify studies connected to sustainability reporting on the development processes of KPIs (key performance indicators) used for measuring sustainability performances and the way in which they are employed in the planning and decisionmaking processes (Adams and Frost, 2008). We also find studies on the reasons for generating sustainability reports (using the semi-structured interview on a sample of entities well-known for "good reporting practices" from the Australian public sector) (Farneti and Guthrie, 2009). Concurring findings on the Australian public sector 
entities are also achieved using a different methodology (i.e. mail survey) (Williams, Wilmhurst and Clift, 2011), whereas other studies present cases for other countries, such as Italy (Montesinos et al., 2013) or Spain (Quiles, Navarro-Galera and Ortiz-Rodriguez, 2013), revealing the GRI guidelines as prevalent for sustainability reporting, as well as significant developments for transparency increment (as a mean to discharge accountability), requiring public administrations to inform citizens about their activities.

The emphasis on the emerging social dimension leads to a structural change from a "vertical" construct to "horizontal" relations between parties engaged in accountability relationships. Moreover, we notice the existence of intermediate bodies which allow communication and interaction between citizens and public administrations. In this sense, power is not contained into one pole, rather it is more widespread, and relations are implicitly more balanced (Bovens 2005; cited by Bartocci and Picciaia, 2013: 194). This leads to a "flattening" and downward enlargement in relations, introducing a horizontal dimension of accountability.

Nowadays, many organizations focus on increasing the availability of information to improve management and provide external accountability. Programs and activities are required to lend themselves to target actual measures. However, one particular area of confusion is the lack of clarity regarding the status of local governments as local administrators of a national performance framework and standards, as opposed to being responsible for local leadership implying accountability in which performance measurement is of paramount importance. The original driver for implementing performance reporting was a desire for accountability enhancement (most of all, for services provided). Recent findings indicate that there is indeed reason to express optimism about the capacity of performance reporting systems to enable accountability and effectiveness in government entities, but the complexity of the process is very high, and it is not as immediate as many advocates would suggest (Cunningham and Harris, 2005).

Therefore, accountability has been the focus of many studies, and it remains a very complex concept, which is not yet fully understood. Moreover, public accountability has come under scrutiny as the new trends in reporting are reaching the public sector. For integrated reporting, this is particularly interesting because regardless of the different levels of complexity, both private and public sector entities have public accountability through their actions. Thus, this concept remains a fundamental principle for public sector entities and should be taken into account when restructuring the reporting system as it may serve as an instrument of know-how transference for $<\mid R>$.

\section{The integrated reporting framework for public sector entities: requirements and challenges}

The $<\mid R>$ Framework - whether in its draft form or the final version - has come under significant scrutiny and discussion regarding its construct (Loska, 2011; Reuter and Messner, 2015). The primary focus of the debates is to assess a level of understanding regarding the political dimension of standard-setting in the context of $\langle\mid R\rangle$ and to reveal different concerns (for instance, the scope of $<\mid R>$ audience; issues of materiality and the relationship between $\langle\mid R\rangle$ and other existing reporting frameworks; assurance provision etc.).

Indeed, integrated reporting is a concept that was primarily designed for the private sector. However, the basic design of an integrated report can be applied to public sector entities as well (see paragraph 1.4 from the IIRC Framework) and is not as restrictive as the phrasing in the Framework appears to be. For instance, if we look at the value creation process through $\langle\mid R\rangle$ (see Fig. 1), we can notice that it is based on flows and elements that are similar in the public sector (such as capitals, activities, inputs, outputs, outcomes). Concepts such as value preservation and capital maintenance would suit well in the case of public sector entities, which function as stewards for public goods. However, to understand this dichotomy, we need to analyse the concept of public value - how it is defined (Moore, 1995); how it works in the context of new public management (O'Flynn, 2007; Alford and Hughes, 2008); where is it framed in the governance systems (Stoker, 2006). Moreover, there are many dimensions which are embedded in the case of value creation (for instance: we analyse that a public sector entity can create value for the public, but can it create value for itself?). 


\section{Figure 1. The value creation process presented in the IIRC Framework}

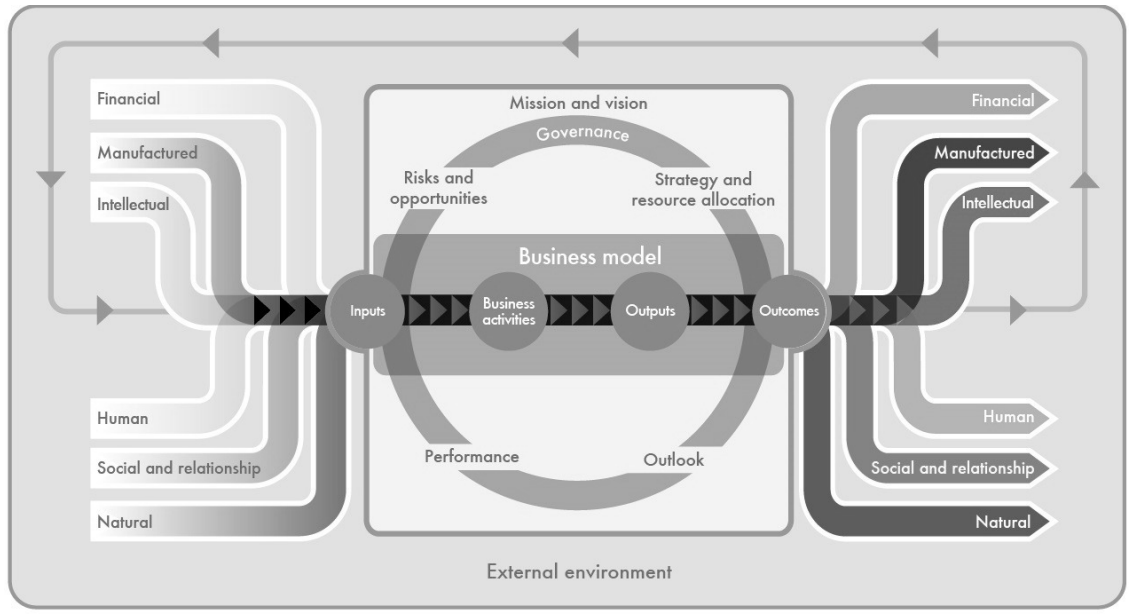

Value creation (preservation, diminution) over time

Source: IIRC, 2013a: p. 7.

Also, the content elements and the principles of $\langle\mid R\rangle$ are not restrictive towards public sector entities, as there is also strategic planning (e.g. public institutions' master plans for 5-7 years), connectivity of information (both horizontally - between agencies on the same level, and vertically - between agencies on different levels), as well as stakeholder inclusiveness.

For implementation in the public sector, we need to question and break down this model in order to analyse whether it is appropriate for the public sector in its current form (with accurate testing for each piece) or it requires certain adjustments (e.g. more/fewer capitals; address resource limitations; insert political dimension in the model). Also, the principles are paramount for the public sector as well (e.g. we need to address what is material for such a report in the public sector; how can conciseness be achieved in mitigation with materiality; which are the stakeholders which need to be engaged).
The strategies and decisions which are disclosed in the $\langle\mathbb{R}>$ should lead to the creation (preservation) of economic and/or sustainable value (with a balance between the two - see Figure 2). Also, it should provide support for the information needs of taxpayers - which are the public sector "shareholders" (although this is rarely crossed in practice) and broaden the timeframe for decisionmaking. Curiously enough, these stakeholders are not the primary users of the reports in the public sector, but the people who work there are.

Considering all the constituting elements of $\langle\mid R\rangle$, we emphasize the fact that, by using Mashaw's taxonomy, we can distinguish this reporting system as an accountability enabler. The only questionable dimension remains connected to the set of standards by which the organization prepares the reports (at this point, the only official guideline document is the Framework). 
Figure 2. The main objectives of $\langle/ R\rangle$

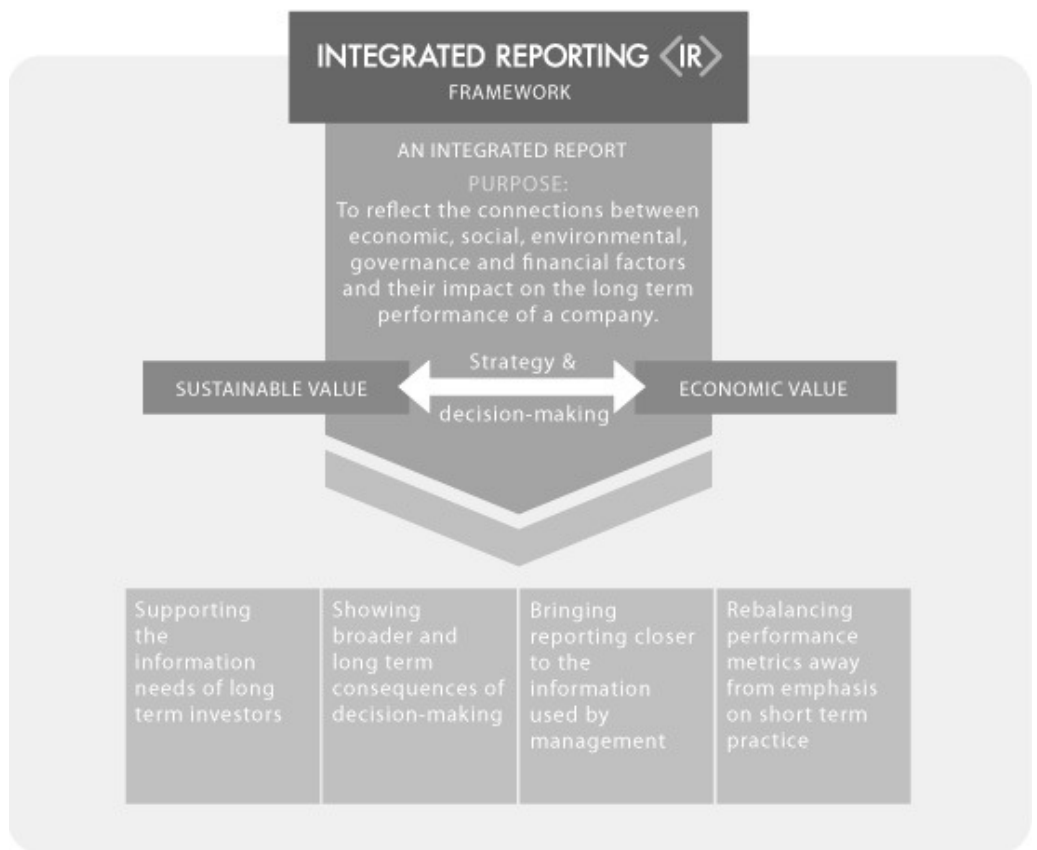

Source: http://blog.aicpa.org/2011/07/integrated-framework-in-the-professions-future.html

All these elements support the fact that, although the two sectors - private and public - are different concerning characteristics, the adoption of integrated reporting is suitable to the same extent. The main focus should come on the fact that the Conceptual Framework should be adapted so that it holds account of the key features and different insights of the public sector, as well. This desiderate is possible and very well supported by public sector professional organizations and standard setters (mainly the ones that actively contributed to the improvement of the Framework in the consultation process from 2013).

\section{Greating the path towards an accountability enhancement tool for public sector entities in the shape of integrated reporting}

Following recent developments regarding $\langle\mathbb{R}\rangle$, we can emphasize its evolution as an independent concept. The emergence of "integrated thinking" and the metamorphosis of sustainability reporting (by endorsing an integrated approach and splitting the triple bottom line model into more layers) have provided the ground 
for advancements towards a new research direction regarding $\langle\mathbb{R}\rangle>$ (Lai, Melloni and Stacchezzini, 2014; Eccles and Saltzman, 2011; Mammat, 2009). Early adopters of $\langle\mid R\rangle$ have presented a lot of interest within this field as they would have preliminary evidence regarding the institutionalization of $\langle\mid R\rangle$. Specifically, they are interested in the framing of their mutations regarding of processes and structures (even though findings show that adoption of $<\mid R>$ has not necessarily stimulated innovations in disclosure mechanisms) (Stubbs and Higgins, 2014; Higgins, Stubbs and Love, 2014).

The natural evolution of the reporting system was to a template outline for $<\mid \mathrm{R}>$ which would be based on "the story of an organization's journey towards reaching its vision", by the $<\mathrm{R}>$ principles, its fundamental concepts, and its content elements. Moreover, $\langle\mid R\rangle$ is viewed as an opportunity for the reporting parts to be summed up in a single holistic construct, presenting information about the "web of interactions and implications of financial, social, environmental, and governance-related organizational activities for stakeholders" (Abeysekera, 2013).

Nevertheless, the implementation and use of $\langle\mathrm{R}\rangle$ have much more complex implications on an organization's activity and its relationship with stakeholders than merely a way of providing a more extensive view of the (created, preserved or depleted) value and the business model. Also, $<\mid R>$ is considered a significant proxy for the overall level of quality of the management (emphasizing the growing interest in intangibles and revealing the "externalities" on the environment and society). "Integrated thinking" - as a distinct concept - is seen as a mechanism to achieve "balance between short-term imperatives and ongoing value creation" (Churet and Eccles, 2014).

Other discussions regarding $\langle\mathbb{R}\rangle$ are focused on the cost-benefit analysis (taking the implementation process into account, with all its constituting elements), as well as collaboration perspectives and the outlook for all sectors in order "to establish a global movement for sustainable actions" (Eccles and Saltzman, 2011). This assumption would frame the implementation of $\langle\mid \mathrm{R}\rangle$ in a much broader web of interactions between different stakeholders.

In close connection, many analyses and studies have been focused on the mandatory/voluntary status of $\langle\mathrm{R}\rangle$ in order to create added-value to reporting (Eccles,
Cheng and Saltzman, 2010), as well as emphasizing and analysing connections with principles and content elements - such as materiality (Eccles et al., 2012; Mio and Fasan, 2014), capitals (Bartolini, Santini and Silvi, 2013) or governance (Wulf, Niemoeller and Rentzsch, 2014), as well as external factors, such as the cultural system (Frías-Aceituno, Rodríguez-Ariza and GarcíaSánchez, 2013; Garcia-Sanchez, Rodríguez-Ariza and Frías-Aceituno, 2013).

In the recent years, the IIRC has undertaken considerable efforts to issue and facilitate the reporting practice of $\langle\mid R\rangle$ through guidelines for implementation. Hence, critical voices have brought up the fact that $\langle\mathbb{R}\rangle$ should "broaden up" and "open up" dialogue, setting the ground for an intense debate on how standardization and guideline issuance might assist or obstruct the core model of "sustainable practices." Using business cases as a primary logic shows the inherent limitation of IIRC's view and many stakeholders demand "a more pluralistic approach, as well as new accounting technologies and engagement practices" (Brown and Dillard, 2014).

Recent studies (Veltri and Silvestri, 2015; Cheng et al., 2014; Bartocci and Picciaia, 2013) highlight the key developments, examples and implementation perspectives for the $\langle\mathbb{R}>$ in the public sector and even synthesize hybrid forms of reporting (such as "integrated popular reporting"), as a mean for safeguarding accountability and transparency (Cohen and Karatzimas, 2015). Consequently, the $<\mid R>$ might be helpful at considering the organization as a whole and unitary functional system, mainly designed for creating value for a broad range of stakeholders (Vermiglio, 2012). Most of the conclusions are in line with the comments provided by the respondents in the consultation process conducted by the IIRC.

In the public sector, a good early adopter of (some form of) $\langle\mid R\rangle$ is the City of Warsaw, which published its first "Integrated Sustainability Report" in 2013 (and the trend is expected to continue, with the perspective of further guidance for public sector entities). Although it is not a "pure" integrated report (as the reporting entity hesitates to call it so), the "integrated sustainability report" from the City of Warsaw is a good example of a hybrid form of reporting (which is the continuing working draft towards the final product). The main reason for producing this report as a hybrid is the fact that it was issued for the year 2013 when the $<\mid R>$ Framework was still in its drafting and consultation process. 
Therefore, the City of Warsaw used the closest reference to \langle|$R>$ in terms of guidelines: the GRI. Apparently, this report is the first ever worldwide issued under $\mathrm{G} 4$ guidelines. The main construct of the report is based on the three pillars of sustainability (environmental, social and economic) and it even extends the encompassment by embedding these pillars in the strategic outlook ("ongoing steps to assure strategic goals are met"). All in all, the report is 14-pages long and does an excellent job in keeping the presentation concise and material (just as the $\langle\mathbb{R}\rangle$ principles state). Still, the most interesting aspect of this report is the great number of KPls used in assessing the activity of the City Administration during the year 2013, providing numbers and percentages for each instance of activity and connected to each line from the GRI Content Index (G4 Guidelines). This leads to a very accurate presentation of the City's results and the performance of the public servants and their activities on each pillar of sustainability, in the context of the main strategies.

This report (alongside others of its kind) represents the consolidation start of this new trend in public sector reporting. Furthermore, CIPFA and the IIRC have announced the establishment of a new international working group: Public Sector Pioneer Network. The oversight of the network is ensured by a steering group, expected to contain a mixture of participants and external organizations, with a secretariat provided by CIPFA and the IIRC. According to its leaders, "the new group will pioneer implementation of $\langle/ R>$ across the various different types of bodies in the public sector to demonstrate how it can be applied and share their experience with others to help improve transparency and accountability, and build trust in the public sector organizations" (CIPFA, 2014).

\section{Figure 3. Benefits of participation in the $\langle\mathbb{R}>$ Public Sector Pioneer Network}

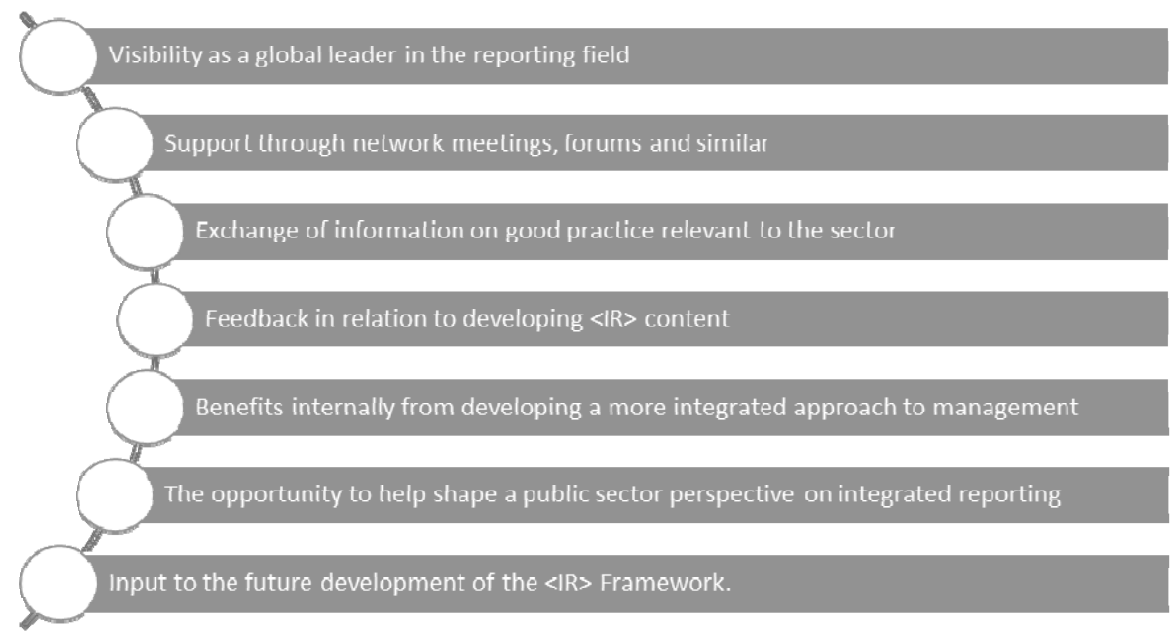

Source: http://www.cipfa.org/policy-and-guidance/integrated-reporting-public-sector-pioneer-network

There is also mentioned that the new pioneer network has the role in facilitating its members to share ideas and learning one from each other as they develop their own approach to integrated reporting. This international working group is expected to function during two reporting cycles 2014/2015. This is intensely promoted by all the founding organizations, but although these initiatives 
are supported, the first reports are significantly delayed in terms of timeframe.

A CIMA report from 2015 shows that the advancements with the Public Sector Pioneer Network are slow. Until the time the report was published, merely seven reporting entities were included as good $\langle\mathbb{R}\rangle$ implementers, and most of them are state-owned enterprises (which, from a sectoral point of view are at the borderline between private and public, but manifest public accountability nevertheless). We expect the number of these reporting entities to rise as the Network is actively expanding and working to address all the challenges for public sector implementation.

On a discursive note, we find that the leaders of this Pioneer Network (through the voice of Bertrand Badré, Group Chief Financial Officer at the World Bank Group, acting as a founding participant) have a rather interesting assessment on how these organizations view integrated reporting in the public sector. The statement (which can be found on the promoting flyer) emphasizes that "[p]ublic sector entities are some of the largest, if not the largest, reporting entities in the world, so the transparency of their financial information is of importance to us all. Integrated Reporting would enable governments and their stakeholders to gain a better understanding of resources available and help them to manage these more effectively" (CIPFA, 2014).

First of all, it is clear that transparency is an issue for public sector entities, and it needs to be addressed (and integrated reporting is seen by the Pioneer Network's drivers as a solution to increase it). Also, the emphasis on financial information is evident, and it leads us to think that the capital providers are not all equally important (the financial capital still gains most of the attention from the preparers). Governments are explicitly mentioned as primary users of these reports (all the other stakeholders being left in one general category). Last, but not least, it is presumed that these reports will be used as management tools, which would improve the way public sector organizations are run. It remains to be seen if the reporting entities run these coordinates in the same understanding.

To this point, it is clear that public sector entities are mandated to work in the public interest and are held publicly accountable for their use of resources, actions and impact of their activity. Thus, an important underlying assumption is that these entities should constantly attempt to reduce information asymmetry and increase transparency. Many theorists and practitioners see $<\mid R>$ as a mean to put in effect this assumption and the trend leads towards this system (whether it evolves naturally - like it is the case of City of Warsaw; or the implementation as part of an interconnected web of stakeholders - like it is the case of the Network itself).

\section{Conclusions}

Integrated reporting has come across great support in the recent years, as most of the professional organizations, standard setters, academics and earlyadopters actively collaborate in finding better ways of achieving its goals and ensuring proper implementation. However, the $\langle\mid \mathbb{R}\rangle$ concept itself is not really a brand new territory, but it looks like a re-emergence of precursor reporting formats - only with an approach from a different angle ("the integrated thinking").

On a conceptual level, integrated reporting applies to entities from all sectors (private, public and nongovernmental); however, the phrasing and the primary design of the Conceptual Framework target this reporting system towards the private sector. This is in no way a restriction to the possible implementation in the public sector, as the Framework can be adapted and, furthermore, professional organizations actively work (in collaboration) to drive the public sector towards $\langle\mid R\rangle$. Therefore, we conclude that $\langle\mid R\rangle$ is indeed suitable for the public sector (having considered the initiatives and views from theorists and practitioners) and could have many implications (among which is also accountability enhancement).

Through our study, we also reveal the main features of the concept of "accountability" in order to understand how this could work as a prerequisite for $\langle\mid R\rangle$. We found many studies that approach different delineations and manifestations of accountability, needed to understand how this trait is perceived in the context of public interest and public services. Using these delineations and taxonomy, we find a match of the dimensions of public accountability with the core construct of $\langle\mid R\rangle$, thus enabling the reporting system as an accountability tool for public sector entities (allowing users to understand and judge the most important aspects of an organization's activity).

The benefits of $\langle\mid R\rangle$ seem to be widely acknowledged and, despite the inherent level of reluctance and negativity, the system is gathering interest from various 
reporting entities (whether or not they are involved in official initiatives, such as the Public Sector Pioneer Network). Thus is the case of the City of Warsaw, which drafted its own "Integrated Sustainability Report" for the year 2013 (by GRI guidelines, but inherently following the key traits of \langle|$R>)$.

The research is ongoing, but we point out key developments and the perspective of developing a new tool for public accountability enhancement (in the form of integrated reporting). The momentum is building, and the evidence is growing that this is a desired reporting system for public sector entities. The main challenges are in terms of guidelines issuance (considering the differences between the sectors and the fact that $\langle\mid R\rangle$ was originally drafted for the private sector) and support for this process from the main "actors" (reporting entities, professional organizations, standard setters).

Fortunately, the second aspect is on a positive trend as these entities have indeed shown interest towards this direction and are actively working on solutions to drive $<\mid R>$ towards the public sector.

The main limitation of this research is that it approaches all the concepts at a documentary level (emphasizing the core assumptions for applying integrated reporting in the public sector). The existing data needed to construct an empirical study is really scarce, and the one that does count is connected solely to the private sector. However, as an outlook, we will drive our research forward-looking and link our efforts to the main initiatives of the professional organizations and standard setters to implement $\langle\mathbb{R}\rangle$ in the public sector (through the Public Sector Pioneer Network).

\section{Acknowledgement}

This work was supported by a grant of the Romanian National Authority for Scientific Research and Innovation, CNCS - UEFISCDI, project number PN-IIRU-TE-2014-4-0265.

\section{REFERENCES}

1. Abeysekera, I. (2013), A template for integrated reporting, Journal of Intellectual Capital, vol. 14, no. 2, pp. 227-245, DOI: http://dx.doi.org/10.1108/14691931311323869.

2. ACCA and NBA, Capitals (2013), Background paper for $<\mid R>$, [pdf] Available at:

http://www.theiirc.org/wp-content/uploads/ 2013/03//R-Background-Paper-Capitals.pdf, [Accessed on February 20, 2015].

3. AccountAbility (2011), Stakeholder Engagement Standard 2011 (AA1000SES), Final Exposure Draft, [pdf] Available at:

http://www.accountability.org/images/content/3/6/3 62/AA1000SES\%202010\%20PRINT.PDF, [Accessed on January 20, 2015].

4. Adams, C. and Frost, G. (2008), Integrating sustainability reporting into management practices, Accounting Forum, vol. 32, no. 4, pp. 288-302, DOI: http://dx.doi.org/10.1016/j.accfor.2008.05.002.

5. AICPA (2011), Integrated Reporting Framework in the Profession's Future, [online] Available at: http://blog.aicpa.org/2011/07/integrated-frameworkin-the-professions-future.html, [Accessed on January 11, 2015].
6. Alford, J. and Hughes, O. (2008), Public Value Pragmatism as the Next Phase of Public Management, The American Review of Public Administration, vol. 38, no. 2, pp. 130-148, DOI: http://dx.doi.org/10.1177/0275074008314203.

7. Bartocci, L. and Picciaia, F. (2013), Towards Integrated Reporting in the Public Sector, in Integrated Reporting: Concepts and Cases that Redefine Corporate Accountability, edited by Busco, C., Frigo, M.L., Quattrone, $P$ and Riccabone, A. (eds.), Springer International Publishing Switzerland, pp. 191-204, DOI: http://dx.doi.org/ 10.1007/978-3-319-02168-3.

8. Bartolini, M., Santini, F. and Silvi, R. (2013), Performance Measurement and Capitals, in Integrated Reporting: Concepts and Cases that Redefine Corporate Accountability, edited by Busco, C., Frigo, M.L., Quattrone, $P$ and Riccabone, A. (eds.), Springer International Publishing Switzerland, pp. 127-145, DOI: http://dx.doi.org/ 10.1007/978-3-319-02168-3.

9. Bovens, M. (2005), Public accountability, in The Oxford handbook of public management, edited by Ferlie, E., Lynne, L.and Pollitt, C. (eds.), Oxford: Oxford University Press. 
10. Brown, J. and Dillard, J. (2014), Integrated reporting: On the need for broadening out and opening up, Accounting, Auditing and Accountability Journal, vol. 2, no. 7, pp. 1120-1156, DOI: http://dx.doi.org/10.1108/AAAJ-04-2013-1313.

11. Burrit, R. (2012), Environmental performance accountability: planet, people, profits, Accounting, Auditing \& Accountability Journal, vol. 25, no. 2, pp. 370-405, DOI: http://dx.doi.org/10.1108/09513571211198791.

12. Cheng, M., Green, W., Conradie, P., Konishi, N. and Romi, A. (2014), The International Integrated Reporting Framework: Key Issues and Future Research Opportunities, Journal of International Financial Management and Accounting, vol. 25, no. 1, pp. 90-119, DOI: http://dx.doi.org/10.1111/jifm.12015.

13. Churet, C. and Eccles, R. (2014), Integrated Reporting, Quality of Management and Financial Performance, Journal of Applied Corporate Finance, vol. 26, no. 1, 2014, pp. 56-64, DOI: http://dx.doi.org/10.1111/jacf.12054.

14. CIMA (2015), Integrated Reporting in the Public Sector, [pdf] Available at: http://www.cimaglobal.com/Documents/Thought_le adership_docs/reporting/IR-Public-Sector.pdf, [Accessed on March 13, 2016].

15. CIMA, IFAC, PricewaterhouseCoopers (2013), Business Model. Background paper for $</ R>$, [pdf] Available at: http://www.theiirc.org/wpcontent/uploads/2013/03/Business_Model.pdf, [Accessed on February 20, 2015].

16. CIPFA (2014), Integrated Reporting: public sector pioneer network, available online: http://www.cipfa.org/policy-and-guidance/articles/ integrated-reporting-public-sector-pioneer-network, [Accessed on June 01, 2014].

17. City of Warsaw (2013), Integrated Sustainability Report, [pdf] Available at: http://www.um.warszawa.pl/sites/default/files/warsa W_g4_integrated_sustainability_report_2013.pdf, [Accessed on February 20, 2015].

18. Cohen, S. and Karatzimas, S. (2015), Tracing the future of reporting in the public sector: introducing integrated popular reporting, International Journal of Public Sector Management, vol. 28, no. 6, pp. 449-460, DOI: http://dx.doi.org/10.2139/ssrn.2524807.
19. Cunningham, G.R. and Harris, J.E (2005), Toward a Theory of Performance Reporting to Achieve Public Sector Accountability: A Field Study, Public Budgeting and Finance, vol. 25, no. 2, pp. 15-42, DOI: 10.1111/j.0275-1100.2005.00359.x.

20. Eccles, R., Cheng, B. and Saltzman, D. (eds.) (2010), The Landscape of Integrated Reporting Reflections and Next Steps, Cambridge: Harvard Business School.

21. Eccles, R. and Saltzman, D. (2011), Achieving Sustainability through Integrated Reporting, Stanford Social Innovation Review, vol. 9, no. 3, pp. 55-61, [pdf] Available at: http://people.hbs.edu/reccles/2011SU_Features_E cclesSaltzman.pdf, [Accessed on March 08, 2014].

22. Eccles, R., Krzus, M., Rogers, J. and Serafeim, G. (2012), The Need for Sector-Specific Materiality and Sustainability Reporting Standards, Journal of Applied Corporate Finance, vol. 24, no. 2, pp. 8-14, DOI: 10.1111/j.1745-6622.2012.00380.x.

23. Farneti, F. and Guthrie, J. (2009), Sustainability Reporting by Australian Public Sector Organizations: Why they Report, Accounting Forum, vol. 33, no. 2, pp. 89-98, DOI:10.1016/j.accfor.2009.04.002.

24. Frías-Aceituno, J.V., Rodríguez-Ariza, L. and García-Sánchez, I.M. (2013), Is integrated reporting determined by a country's legal system? An exploratory study, Journal of Cleaner Production, vol. 44, pp. 45-55, DOI:10.1016/j.jclepro.2012.12.006.

25. Garcia-Sanchez, I. M., Rodriguez-Ariza, L. and Frias-Aceituno, J.V. (2013), The cultural system and integrated reporting, International Business Review, vol. 22, no. 5, pp. 828-838, DOI:10.1016/j.ibusrev.2013.01.007.

26. Higgins, C, Stubbs, W. and Love, T. (2014), Walking the talk(s): Organisational narratives of integrated reporting, Accounting, Auditing \& Accountability Journal, vol. 27, no. 7, pp. 10901119, DOI: http://dx.doi.org/10.1108/AAAJ-042013-1303.

27. IIRC (2013a), The Consultation Draft of the International $<\mid R>$ Framework, [pdf] Available at: $\mathrm{h}$ http://integratedreporting.org/wpcontent/uploads/2013/03/Consultation-Draft-of-the- 
InternationallRFramework.pdf , [Accessed on June 13, 2016].

28. IIRC (2013b), The International $<\mid R>$ Framework, [pdf] Available at: http://www.theiirc.org/wpcontent/uploads/2013/12/13-12-08-THEINTERNATIONAL-IR-FRAMEWORK-2-1.pdf, [Accessed on March 06, 2014].

29. KPMG (2012), Integrated Reporting: Performance insight through Better Business Reporting, [pdf] Available at: http://www.kpmg.com/Global/en/ IssuesAndlnsights/ArticlesPublications/Documents/ road-to-integrated-reporting.pdf [Accessed on March 10, 2014].

30. Lai, A., Melloni, G. and Stacchezzini, R. (2014), Corporate Sustainable Development: is 'Integrated Reporting' a Legitimation Strategy?, Business Strategy and the Environment, vol. 25, no. 3, pp. 165-177, DOl: http://dx.doi.org/10.1002/bse.1863.

31. Loska, T. (2011), Integrated Reporting: Towards a Framework for a Sustainable International Corporate Reporting, Master's Thesis, [online] Available at: http://www.grin.com/en/ebook/184164/integrated-reporting-towards-aframework-for-a-sustainable-international, [Accessed on June 13, 2016].

32. Mammat, J. (2009), Integrated Sustainability Reporting and Assurance, CIS Corporate Governance Conference, 2009, pp. 1-6, [pdf] Available at: http://icsa.co.za/documents/ speakerPres/JayneMammat/MammattIntegratedSu stainabilityReportingandAssurance.pdf [Accessed on March 08, 2014].

33. Mashaw, J. L. (2006), Accountability and institutional design: some thoughts on the grammar of governance, in Public Accountability: Designs, Dilemmas and Experiences, edited by Dowdle, M.W., Cambridge: Cambridge University Press, pp. 115-156.

34. Mio, C. and Fasan, M. (2013), The determinants of materiality disclosure in integrated corporate reporting, Working papers series, no. 2014/9, Universita Ca' Foscari, Venezia, [pdf] Available at: http://papers.ssrn.com/sol3/papers.cfm?abstract_id $=2443929$, DOI: http://dx.doi.org/10.2139/ ssrn.2443929 [Accessed on June 13, 2016].

35. Montesinos, V., Brusca, I., Manes Rossi, F. and Aversano, N. (2013), Sustainability Reporting in Local Governments. A Comparison between Italy and Spain, CIGAR Conference Proceedings.
36. Moore, M. (1995), Creating Public Value: Strategic Management in Government, Cambridge: Harvard University Press.

37. O'Flynn, J. (2007), From New Public Management to Public Value: Paradigmatic Change and Managerial Implications, The Australian Journal of Public Administration, vol. 66, no. 3, pp. 353-366, DOI: 10.1111/j.1467-8500.2007.00545.x.

38. Quiles, F.J.A., Navarro-Galera, A. and OrtizRodriguez, D. (2013), The disclosure of information about sustainability at the regional governments and influencing factors: the case of Spain, EAA Doctoral Colloquium.

39. Patton, J.M. (1992), Accountability and Governmental Financial Reporting, Financial Accountability and Management, vol. 8, no. 3, pp. 165-180, DOI: 10.1111/j.14680408.1992.tb00436.x.

40. Raga, K. and Taylor, D. (2005), Impact of Accountability and Ethics on Public Service Delivery: A South African Perspective, Public Manager, [pdf] Available at: http://www.aspaonline. org/global/V34N2_ImpactOfAccountability_Taylor.p df, [Accessed on February 20, 2015].

41. Reuter, M. and Messner, M. (2015), Lobbying on the integrated reporting framework: An analysis of comment letters to the 2011 DP of the IIRC, Accounting, Auditing \& Accountability Journal, vol. 28, no. 3, pp. 365-402, DOI: http://dx.doi.org/10.1108/AAAJ-03-2013-1289.

42. Stewart, J.D. (1984), The role of information in public accountability, in Issues in Public Sector Accounting, edited by Hopwood, A., Tomkins, C., Oxford: Phillip Allen Publishing, pp. 13-34.

43. Steyn, B. and de Beer, E. (2012), Strategic role of public relations in the process of 'integrated reporting' - An exploratory study, Sinergie, rivista di studi e ricerche, vol. 88, pp. 53-72, DOI: http://dx.doi.org/10.7433/679.

44. Stoker, G. (2006), Public Value Management. A New Narrative for Networked Governance?, American Review of Public Administration, vol. 36, no. 1, pp. 41-57, DOI: http://dx.doi.org/10.1177/0275074005282583.

45. Stubbs, W. and Higgins, C. (2014), Integrated Reporting and internal mechanisms of change, 
Accounting, Auditing \& Accountability Journal, vol. 27, no. 7, pp. 1068-1089, DOI: http://dx.doi.org/10.1108/AAAJ-03-2013-1279.

46. Synergiz (2014), What Natural Capital Disclosure for Integrated Reporting?, [pdf] Available at: http://www.acts-net.org/images/Pubs/Working Papers/What-Natural-Capital-disclosure-forintegrated-reporting-Synergiz-ACTS-2014.pdf, [Accessed on February 20, 2015].

47. Veltri, S. and Silvestri, A. (2015), The Free State University integrated reporting: a critical consideration, Journal of Intellectual Capital, vol. 16, no. 2, pp. 443-462, DOI: http://dx.doi.org/10.1108/JIC-06-2014-0077.

48. Vermiglio, C. (2012), Integrated reporting for Italian local governments. Background for debate, Financial Reporting Workshop, Naples, [pdf] Available at:
http://www.frworkshop.com/napoli/eng/papers/Ver miglio.pdf, [Accessed on June 13, 2016].

49. WICI (2013), Connectivity. Background paper for $</ R>$, [pdf] Available at: http://www.theiirc.org/wpcontent/uploads/2013/07/IR-Background-PaperConnectivity.pdf, [Accessed on February 20, 2015].

50. Williams, B., Wilmhurst, T. and Clift, R. (2011), Sustainability reporting by local government in Australia: Current and future prospects, Accounting Forum, vol. 35, no. 3, pp. 176-186, DOI: doi: 10.1016/j.accfor.2011.06.004.

51. Wulf, I., Niemoeller, J. and Rentzsch, N. (2014), Development toward integrated reporting, and its impact on corporate governance: a twodimensional approach to accounting with reference to the German two-tier system, Journal of Management Control, vol. 25, no. 2, pp. 135-164, DOI: http://dx.doi.org/10.1007/s00187-014-0200-z. 